\title{
Does Frequency of ST-Segment Elevation Myocardial Infarction Presentation Impact Quality of Care?
}

Alex N. Mazurek ${ }^{1}$, Paul R. Atkinson ${ }^{2}$, Jaroslav Hubacek ${ }^{3}$, Mark McGraw ${ }^{4}$, Sohrab Lutchmedial $^{3}$

1. Family Medicine, Saint John Regional Hospital/Dalhousie University 2. Emergency Medicine, Saint John Regional Hospital/Dalhousie University, Saint John, CAN 3. New Brunswick Heart Centre, Saint John Regional Hospital/Dalhousie University 4. Student, Saint John Regional Hospital

$\square$ Corresponding author: Paul R. Atkinson, paul.atkinson@dal.ca

Disclosures can be found in Additional Information at the end of the article

\section{Abstract}

\section{Objectives}

The volume of ST-Segment Elevation Myocardial Infarctions (STEMIs) presenting to an emergency department (ED) has been shown to affect treatment quality measures and patient outcomes. Almost half of ST-elevation-myocardial-infarction (STEMI) patients in New Brunswick (NB) present directly to community hospitals. This study seeks to determine if the quality of care received by STEMI patients presenting to EDs in NB is related to the volume of STEMI presentations at that center.

\section{Methods}

This retrospective registry-based study used data from the STEMI database at the New Brunswick Heart Centre (NBHC), identifying 1196 cases of STEMI in NB, Canada, between December 2010 and April 2013. Patients were stratified into three groups based on the annual volume of STEMIs seen at the presenting center. Quality of care determinants, consisting of the percent of cases adhering to door-to-ECG (D2E), ECG-to-needle (E2N), and door-to-needle (D2N) time guidelines were then compared between groups.

\section{Results}

The mean age of the 1188 cases identified was 61.3 years, $73.8 \%$ were male, and $69.0 \%$ received thrombolysis. There was no difference in the rate of guideline adherence between the high, medium, and low-volume centers. The total rates of guideline adherence were $43.7 \%, 44.9 \%$, and $47.5 \%$ for the D2E, E2N, and D2N times, respectively.

Received 08/17/2017

Review began 11/17/2017 Review ended 11/21/2017 Published 11/26/2017

\section{(c) Copyright 2017}

Mazurek et al. This is an open access article distributed under the terms of the Creative Commons Attribution License CC-BY 3.0., which permits unrestricted use, distribution, and reproduction in any medium, provided the original author and source are credited.

\section{Conclusion}

We did not identify any relationship between the rates of adherence with STEMI care guidelines and the volume of STEMI patients presenting to a center. Adherence rates were lower than in previously reported series from other regions. Further efforts should be undertaken to identify the causes of delayed STEMI diagnosis and treatment in our population and to implement system changes to improve standards of care.

Categories: Cardiology, Emergency Medicine 
Keywords: myocardial infarction, electrocardiogram, quality, emergency care

\section{Introduction}

Advances in ST-elevation myocardial infarction (STEMI) care have resulted in improved reperfusion times and, consequently, a reduction in overall mortality [1]. However, STEMIs are still a major contributor to the overall burden of cardiovascular disease, with contemporary 30day and 1-year mortality of approximately $4 \%-9 \%$ and $7 \%-13 \%$, respectively [2-3]. Modern clinical practice guidelines now generally recommend three possible reperfusion strategies for patients presenting within 12 hours of symptom onset, depending on local resources and expected treatment delay:

1. Primary percutaneous coronary intervention (pPCI) if the expected delay from first medical contact (FMC) to device deployment is less than 120 minutes;

2. Fibrinolysis (unless contraindicated) within 30 minutes of hospital arrival (if logistically unable to achieve pPCI), followed by urgent transfer to a PCI-capable facility for rescue PCI in patients with clinical evidence of failed reperfusion; or

3. Fibrinolysis followed by transfer for routine cardiac catheterization and angioplasty, as indicated, if clinical reperfusion was achieved (pharmaco-invasive approach) [4-5].

Many health regions in Canada cannot meet the strict criteria for pPCI, as only $63.9 \%$ of the population over 40 years of age lives within 60 minutes of a PCI-capable facility [6]. Additionally, timely access to pPCI in New Brunswick, Newfoundland, and Nova Scotia, the Atlantic Canadian provinces, is limited to $15.8 \%$, 32.8\%, and $36.8 \%$ of the population, respectively [6]. This geographic challenge, intrinsic to the sparsely populated Canadian landscape, has generated interest in describing real-world pPCI and fibrinolysis outcomes to ensure the optimization of STEMI care regardless of the population density of a region. Rural hospitals unable to meet the criteria for pPCI rely on a pharmaco-invasive (PhI) approach to STEMI management [7-8].

The short-term safety of this approach has been demonstrated previously in a prospective cohort study by Larson et al., which indicated no difference in 30-day mortality, stroke, reinfarction, or major bleeding between a cohort of patients in rural Minnesota receiving early fibrinolysis followed by immediate transfer for PCI, to those receiving pPCI [7]. The recently published EARLY-MYO randomized control trial also supported this approach and indicated that an early PhI strategy using early fibrinolytic followed by PCI was comparable to pPCI in low-risk patients [8]. Based on the growing support for early fibrinolysis and the knowledge that fewer than 9\% of inter-hospital transfers meet the guidelines for door-to-balloon (D2B) time [9], the American College of Cardiology (ACC)/American Heart Association (AHA) now strongly recommends that in STEMI, fibrinolysis be administered early, unless contraindicated, followed by transfer to a PCI-capable hospital if there is an anticipated delay of 120 minutes from FMC to performing pPCI [4].

The most important determinant of STEMI outcome is time to reperfusion [10-11]. It has been demonstrated that for each 10-minute delay in door-to-needle (D2N) and D2B time, 6-month STEMI-related mortality increases by $0.3 \%$ and $0.18 \%$, respectively [12]. Therefore, contemporary guidelines recommend that systemic delays be minimized to reduce total ischaemic time; specifically, that door-to-electrocardiogram (D2E) time be less than 10 minutes, D2N time less than 30 minutes, D2B time less than 90 minutes, and that regional STEMI care systems should strive for $90 \%$ adherence with these guidelines [13]. Unfortunately, it has been extremely challenging for centers to meet the ACC/AHA's 
guidelines in practice, as evidenced by the reported low adherence with D2E and D2N guidelines in urban settings of $41 \%$ and $26 \%-47 \%$ of the cases, respectively [14-16] and mean D2E and E2N times of 8 minutes and 27 minutes, respectively [17].

Since almost half of STEMI patients present initially to emergency departments (EDs) in community hospitals, often staffed by family physicians [18-19] rather than tertiary referral centers, it is critical to determine if patients presenting with STEMI to community hospitals have similar treatment and outcomes. Recent research in Ontario has indicated that STEMI patients presenting to a low-volume center had a higher risk of being assigned a low triage priority, which, in turn, could be associated with delayed adherence to STEMI care guidelines [20-21]. Since extrapolation to the patients in New Brunswick, Canada, is unclear, the current study aimed to present an overview of STEMI care in the province and to investigate whether there were differences in quality outcomes, such as D2E, D2N, and ECG-to-needle (E2N) times between the tertiary referral centers and smaller community hospitals in the province.

\section{Materials And Methods}

\section{Study design}

This is a retrospective registry-based study with data drawn from the STEMI database of the New Brunswick Heart Centre (NBHC) at the Saint John Regional Hospital (SJRH), the tertiary cardiac referral center in Saint John, NB, Canada. Ethics approval was granted by the regional research ethics board. An independent investigator collected and analyzed relevant data from the database, including all patients referred to the NBHC with a diagnosis of STEMI between December 31, 2010, and April 30, 2013, regardless of treatment modality. The investigator was also blinded to the identity of individual hospitals. Hospitals were grouped together by volume into high ( $\mathrm{H}$, greater than 50 STEMIs seen per year), medium (M, 20-50 STEMIs per year), and low (L, fewer than 20 STEMIs seen per year) centers. Cases were excluded if the referral center was not documented in the NBHC database. Further, for D2E and D2N determination, cases were excluded from the analysis if ECG changes initially resolved and then recurred, the presenting ECG was nondiagnostic for STEMI and was not recorded, it was a non-cardiac presentation, or the initial time of presentation could not be determined. The primary endpoint of the study was to compare the percentage of cases adhering to ACC/AHA 2013 guidelines for the D2E ( $\leqslant 10$ mins), D2N ( $\leqslant 30$ mins), and E2N ( $\leqslant 20$ mins) times between the three groups. Since analysis of D2N and E2N times requires the patient to have undergone fibrinolysis, patients who did not undergo fibrinolysis were excluded from that part of the study.

For the most part, D2E times could easily be calculated, but because emergency medical service (EMS) providers do not perform prehospital 12-lead ECGs (PHECG) in New Brunswick, it was determined that for patients presenting to the hospital by ambulance, the time of first medical contact had to be set as the time the patient was registered in hospital as opposed to the time EMS providers attended on scene. Missing data were assumed to be outside our target values and were handled by assigning a label of "not within guidelines" and including it in the analysis.

\section{Practice setting}

The New Brunswick Heart Centre at the Saint John Regional Hospital sees an annual STEMI volume of approximately 500 cases and is the only center in the province with the infrastructure required to deliver PCI. Therefore, STEMI cases identified and initially treated in the province's 28 other hospitals and health centers are transferred to the NBHC for further workup and eventual angiography. Due to the widely distributed population within the province, it is estimated that only $15.8 \%$ of the population lives within 60 minutes of the NBHC. 


\section{Database description}

The NBHC has been prospectively tracking the delivery of care outcomes for STEMI patients presenting to the SJRH or transferred to the NBHC from other facilities since December 31, 2010. Treatment of STEMIs in hospitals outside of the NBHC is by protocol-based fibrinolysis (unless contraindicated) prior to transport to the NBHC. Patients are required to have symptom duration of less than 12 hours and ST-segment elevation greater than $1 \mathrm{~mm}$ in at least two contiguous leads to be included in the database. Full dose, weight-adjusted tenecteplase 30-50 $\mathrm{mg}$ intravenous (IV) bolus is administered in addition to loading doses of aspirin $325 \mathrm{mg}$ PO and clopidogrel $300 \mathrm{mg}$ PO (75 mg PO if older than 75 years). Patients are then anticoagulated with enoxaparin (30 mg IV bolus followed by $1 \mathrm{mg} / \mathrm{kg}$ SC 15 minutes later) or heparin ( 60 units/kg IV bolus followed by 12 units $/ \mathrm{kg} / \mathrm{hr}$ infusion). Transport to the NBHC is then facilitated as soon as possible and angiography arranged within 24 hours for those who undergo successful fibrinolysis or urgently for those who did not reperfuse as per clinical criteria. Patients presenting directly to the SJRH received either pPCI or fibrinolysis, according to local guidelines.

The current database tracks date of birth, gender, time of first presentation, mode of presentation, time of diagnostic ECG, time of fibrinolysis, time of presentation to the NBHC, time of angiography/PCI, reason for PCI (fibrinolysis failure, facilitated PCI, or pPCI), time of reperfusion, infarct location, other treatments (e.g., surgical management), length of stay, discharge disposition, and will eventually be linked with Vital Statistics NB for mortality outcomes. All patients with STEMI referred to the NBHC are included in the database regardless of treatment.

\section{Statistical analysis}

Comparisons of population characteristics and primary endpoints between the three hospital sizes were performed using one-way analysis of variance (ANOVA) for continuous and normally distributed variables and the chi-squared test for categorical variables. Normality was determined using the Shapiro-Wilk test for normality of data, and Levene's test was used to confirm the homogeneity of variances. For comparison of non-normally distributed data, the nonparametric Kruskal-Wallis H test (one-way ANOVA) was used. Statistical significance was defined as a p-value of less than 0.05 . Statistical analyses were conducted with IBM Statistical Package for the Social Sciences (SPSS) software version 17.0 for Windows. Numerical data were reported as mean \pm standard deviation (SD) for normally distributed data and when data were non-normally distributed, the 90th percentile value was also reported.

\section{Results}

During the study period, 1196 patients with STEMI were recorded in the NBHC STEMI database. Eight of these patients were excluded, as their presenting hospital was unknown, resulting in 1188 eligible study patients. The mean age was $61.3 \pm 12$ years and 875 patients were male (74\%). The overall annual incidence of STEMIs presenting through the NBHC was 509. Province-wide, 820 (69\%) patients underwent fibrinolysis during the study period and were then eligible for the E2N and D2N quality of care analyses. A total of 58, eight, and 41 cases were excluded from the D2E, E2N, and D2N analyses, respectively. Figure 1 provides a breakdown of patient allocation and exclusions. 


\section{Cureus}

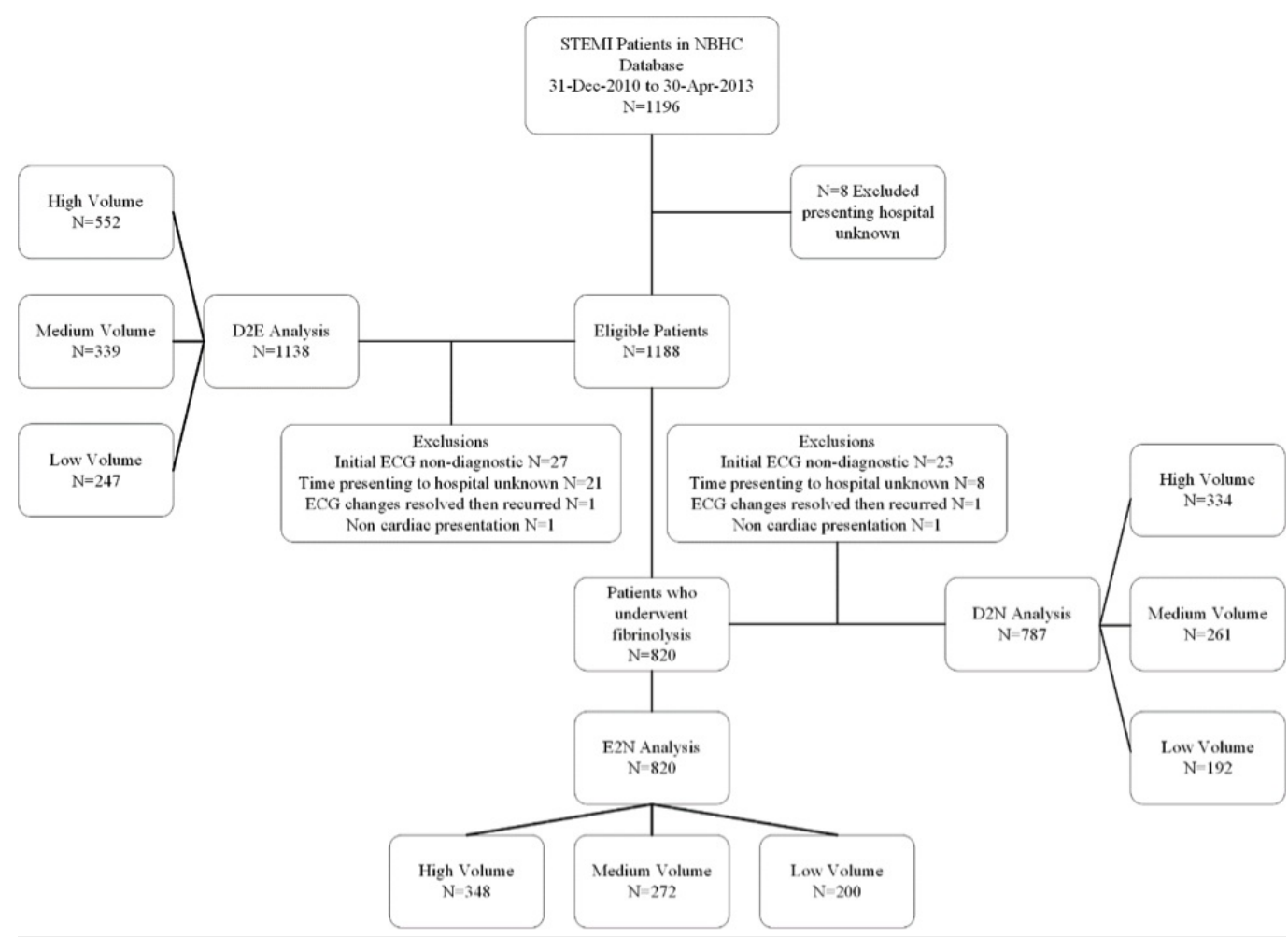

FIGURE 1: Study flow diagram showing the analysis of door-toECG (D2E); ECG-to-needle (E2N); and door-to-needle (D2N) times

NBHC: New Brunswick Heart Centre; D2E: door-to-ECG; E2N: ECG-to-needle; D2N: door-toneedle; High Volume: greater than 50 STEMIs/year; Medium Volume: 20-50 STEMIs/year, Low Volume: less than 20 STEMIs/year

The two most common reasons that cases were excluded was missing time of FMC and initial ECGs that were nondiagnostic and not recorded in the database. Presentation to the hospital was predominantly by walk-in (457 (38\%)) or by ambulance (416 (35\%)). For all eligible patients, the mean D2E time was $22.4 \pm 70.6$ minutes, the 90th percentile D2E time was 32 minutes and was within guidelines in 497 cases (43.7\%). The mean D2N time was $46.9 \pm 58.9$ minutes, the 90th percentile D2N time was 85 minutes and was within guidelines in 374 (47.5\%) of the time. Finally, the mean E2N time was $29.0 \pm 32.4$ minutes, the 90th percentile E2N time was 57 minutes and was within guidelines in 368 (44.9\%) of cases. Table 1 outlines key patient characteristics. 


\section{Cureus}

\begin{tabular}{|c|c|c|c|c|c|}
\hline Characteristics & $\begin{array}{l}\text { All Patients } \\
\mathrm{N}=1188\end{array}$ & $\begin{array}{l}\text { High Volume } N=573 \\
(48.2 \%)\end{array}$ & $\begin{array}{l}\text { Medium Volume } \mathrm{N}=357 \\
(30.1 \%)\end{array}$ & $\begin{array}{l}\text { Low Volume } \mathrm{N}=258 \\
(21.7 \%)\end{array}$ & $\begin{array}{l}\mathrm{p}- \\
\text { value }\end{array}$ \\
\hline $\begin{array}{l}\text { Number of } \\
\text { centers, } \mathrm{N}(\%)\end{array}$ & $28(100)$ & $3(10.7)$ & $5(1 / .9)$ & $20(/ 1.4)$ & $<0.001$ \\
\hline $\begin{array}{l}\text { STEMIs/year, } \\
\text { mean } \pm \text { sd }\end{array}$ & $509 \pm 25.5$ & $81.9 \pm 18.7$ & $30.6 \pm 5.9$ & $5.7 \pm 5.8$ & $<0.001$ \\
\hline Age, mean \pm sd & $61.3 \pm 12.0$ & $61.5 \pm 12.2$ & $61.1 \pm 11.8$ & $61.1 \pm 11.8$ & 0.785 \\
\hline $\begin{array}{l}\text { Male gender, } N \\
(\%)\end{array}$ & $875(73.8)$ & $412(72.0)$ & $268(75.3)$ & 195 (75.9) & 0.386 \\
\hline Fibrinolysis, N (\%) & $820(69.0)$ & $348(60.7)$ & $272(76.2)$ & $200(77.5)$ & 0.004 \\
\hline \multicolumn{6}{|l|}{$\begin{array}{l}\text { Presentation, N } \\
(\%)\end{array}$} \\
\hline Walk-in & $457(38.5)$ & $207(36.1)$ & $137(38.4)$ & $113(43.8)$ & 0.238 \\
\hline Ambulance & $416(35.0)$ & $237(41.4)$ & $99(27.7)$ & $80(31.0)$ & 0.002 \\
\hline Inpatient & $31(2.6)$ & $16(2.8)$ & $13(31.0)$ & $2(0.8)$ & 0.067 \\
\hline Outpatient & $2(0.2)$ & $1(0.2)$ & $0(0)$ & $1(0.4)$ & 1 \\
\hline Unknown & $280(23.6)$ & $111(19.4)$ & $108(30.3)$ & $61(23.6)$ & 0.004 \\
\hline Other & $2(0.2)$ & $1(0.2)$ & $0(0)$ & $1(0.4)$ & 1 \\
\hline
\end{tabular}

TABLE 1: Patient characteristics

\section{Comparison of characteristics between center volume}

Of the 1188 eligible patients, 573 (48.2\%) from three hospitals were allocated to the $\mathrm{H}$ volume group, 357 (30.1\%) from five hospitals to the M volume group, and 258 (21.7\%) from 20 hospitals to the L volume group. The annual incidence of STEMI in each group was $81.9(\mathrm{H})$, $30.6(\mathrm{M})$, and 5.7 (L) units per year. The three groups had similar age, gender, proportion of walk-in, and inpatient presentation. The H volume group had a higher rate of presentation by ambulance than the $\mathrm{M}$ and $\mathrm{L}$ volume centers (41.4\% vs. $37.7 \%$ \& 31.0\%, respectively, $\mathrm{p}=0.002$ ).

\section{Comparison of STEMI quality of care determinants between center volume}

Door-to-ECG times were similar between the three groups (see Table 2). The mean D2E times were 20.1 $\pm 46.0,27.8 \pm 110.9$, and $20.2 \pm 70.6$ for the $\mathrm{H}, \mathrm{M}$, and L volume centers, respectively $(\mathrm{p}=$ 0.548). The 90th percentile D2E times were 29, 33, and 39 minutes for the centers, respectively, and all three groups had very similar rates of adherence to guidelines ranging between $42 \%$ $45 \%(\mathrm{p}=0.823)$. 


\section{Cureus}

\begin{tabular}{|c|c|c|c|c|c|}
\hline & $\begin{array}{l}\text { All Patients } \\
(\mathrm{N}=1138)\end{array}$ & $\begin{array}{l}\text { High Volume } \\
(\mathrm{N}=552)\end{array}$ & $\begin{array}{l}\text { Medium Volume } \\
(\mathrm{N}=339)\end{array}$ & $\begin{array}{l}\text { Low Volume } \\
(\mathrm{N}=247)\end{array}$ & $\begin{array}{l}p- \\
\text { value }\end{array}$ \\
\hline $\begin{array}{l}\text { D2E (mins), } \\
\text { mean } \pm s d\end{array}$ & $22.4 \pm 70.6$ & $20.1 \pm 46.0$ & $27.8 \pm 110.9$ & $20.2 \pm 70.6$ & 0.548 \\
\hline $\begin{array}{l}\text { D2E (mins) } 90^{\text {th }} \\
\% \text { ile }\end{array}$ & 32 & 29 & 33 & 39 & - \\
\hline $\begin{array}{l}\text { D2E adherence N } \\
\text { (\%) }\end{array}$ & 497 (43.7) & $236(42.8)$ & 151 (44.5) & $110(44.5)$ & 0.832 \\
\hline
\end{tabular}

TABLE 2: Comparison of door-to-ECG (D2E) times and adherence to guidelines by center volume

Fibrinolysis-specific quality of care determinants were also similar between the three groups, as outlined in Table 3 and Table 4, except for a small but significant difference in E2N times.

\begin{tabular}{|c|c|c|c|c|c|}
\hline & $\begin{array}{l}\text { All Patients } \\
(\mathrm{N}=\mathbf{8 2 0})\end{array}$ & $\begin{array}{l}\text { High Volume } \\
(\mathrm{N}=348)\end{array}$ & $\begin{array}{l}\text { Medium Volume } \\
(\mathrm{N}=272)\end{array}$ & $\begin{array}{l}\text { Low Volume } \\
(\mathrm{N}=200)\end{array}$ & $\begin{array}{l}\mathrm{p} \text { - } \\
\text { value }\end{array}$ \\
\hline $\begin{array}{l}\text { E2N (mins), } \\
\text { mean } \pm \text { sd }\end{array}$ & $29.0 \pm 32.5$ & $27.4 \pm 29.0$ & $27.1 \pm 30.8$ & $34.1 \pm 39.0$ & 0.008 \\
\hline $\begin{array}{l}\text { E2N (mins) } 90^{\text {th }} \\
\% \text { ile }\end{array}$ & 57 & 49 & 51 & 64 & - \\
\hline $\begin{array}{l}\text { E2N adherence } \mathrm{N} \\
(\%)\end{array}$ & $367(44.8)$ & $156(44.8)$ & $131(48.2)$ & $80(40.0)$ & 0.212 \\
\hline
\end{tabular}

TABLE 3: Comparison of ECG-to-needle (E2N) times and adherence to guidelines by center volume 


\section{Cureus}

\begin{tabular}{|c|c|c|c|c|c|}
\hline & $\begin{array}{l}\text { All Patients } \\
(\mathrm{N}=787)\end{array}$ & $\begin{array}{l}\text { High Volume } \\
(\mathrm{N}=334)\end{array}$ & $\begin{array}{l}\text { Medium Volume } \\
(\mathrm{N}=261)\end{array}$ & $\begin{array}{l}\text { Low Volume } \\
(\mathrm{N}=192)\end{array}$ & $\begin{array}{l}\mathrm{p}- \\
\text { value }\end{array}$ \\
\hline $\begin{array}{l}\text { D2N (mins), } \\
\text { mean } \pm s d\end{array}$ & $46.9 \pm 58.9$ & $46.5 \pm 61.2$ & $45.8 \pm 60.8$ & $49.2 \pm 51.9$ & 0.523 \\
\hline $\begin{array}{l}\text { D2N (mins) } 90^{\text {th }} \\
\text { \%ile }\end{array}$ & 85 & 81 & 78 & 105 & - \\
\hline $\begin{array}{l}\text { D2N adherence } \mathrm{N} \\
\text { (\%) }\end{array}$ & $374(47.5)$ & $168(50.3)$ & 125 (47.9) & $81(42.2)$ & 0.198 \\
\hline
\end{tabular}

TABLE 4: Comparison of door-to-needle (D2N) times and adherence to guidelines by center volume

Low volume centers had a mean E2N time of $34.1 \pm 39.0$ minutes as compared to $27.1 \pm 30.8$ for M, and $27.4 \pm 29.0$ for $\mathrm{H}(\mathrm{p}=0.008)$. There was a similar difference in the 90th percentile E2N times of 49, 51, and 64 minutes for the $\mathrm{H}, \mathrm{M}$, and L groups, respectively. Despite this difference, there was no significant difference in the rate of adherence to E2N guidelines between the three groups with adherence rates ranging from $40 \%-48 \%(\mathrm{p}=0.212)$. There was also no significant difference in D2N times or adherence to guidelines. The mean D2N times were $46.5 \pm 61.2$, $45.8 \pm 60.8$, and $49.2 \pm 51.9$ minutes for the $\mathrm{H}, \mathrm{M}$, and $\mathrm{L}$ volume groups $(\mathrm{p}=0.523)$ and the 90 th percentile times for the groups were 81, 78, and 105 minutes, respectively. Adherence to D2N guidelines ranged from $42.2 \%(\mathrm{~L})$ to $50.3 \%(\mathrm{H})(\mathrm{p}=0.198)$.

\section{Discussion}

This study demonstrated no difference in the adherence to STEMI guidelines between the high, medium-, and low-volume centers in New Brunswick. Adherence was fairly uniform across the three quality measures tested, ranging from $40 \%-50 \%$ and in line with estimates from published retrospective data that indicate $26 \%-47 \%$ adherence [14-16]. There was a significant difference in the mean E2N time across groups; however, this did not affect the E2N adherence to guidelines. Despite adherence data being in line with comparable retrospective publications, all three quality measures in this study (D2E 22.4, E2N 29.0, and D2N 46.9 minutes) were longer than currently published estimates from other centers where D2E, E2N, and D2N times ranged from 6.8 to $18.7,18.7$ to 27.0 , and 29 to 46 minutes respectively [1,14,17,22].

The increased D2E time in this study may be influenced by the lack of initial nondiagnostic ECGs in the NBHC database. Since a small fraction of cases in the study had one or more nondiagnostic ECGs that went undocumented, a small amount of bias would have been introduced that might have artificially underestimated the rate of adherence to D2E time guidelines in our population. Given that previous studies have demonstrated that STEMI guideline concordance improves when the first ECG is diagnostic for a STEMI [15], it would have been helpful to have the initial ECG documented in the NBHC database. Prolonged D2E times are associated with increased D2N and D2B times and subsequent increases in 30-day mortality for patients presenting with nontraumatic STEMIs [16-18]. Studies concerning the improvement of D2E times have shown that low-cost measures focused on the initial point of contact for patient presentation can have a dramatic effect on STEMI quality of care. In one study, allowing ED registration staff to initiate the ECG request resulted in a 7-minute 
reduction in mean D2E time and increased D2E guideline adherence from 16\% to 64\% [23]. A similar study found that having a trained ECG technician greeting patients arriving at the ED and asking about their chief complaint resulted in a 20.8-minute reduction in D2E time [24]. Triage acuity has also been shown to affect D2E times for STEMI patients [20-21]. An Ontario study found that $25 \%$ of patients presenting with a STEMI were assigned a low triage priority, resulting in a 12.2-minute increase in D2E time and a 20.7-minute increase in D2N time [2021]. Given the results of these studies, it is conceivable that a clinically significant reduction in D2E time for our study population could be achieved by implementing low-cost, frontline measures aimed at earlier ECG activation and recognition of patients at high risk for STEMI during triage.

The rate of fibrinolysis therapy in our study was $69.0 \%$, substantially higher than the national average of $27.6 \%$. This is not surprising given that only $15.8 \%$ of the population in New Brunswick over the age of 40 lives within 60 minutes of the NBHC [6]. Unfortunately, the mean D2N time in our study was 46.9 minutes, higher than other published estimates that ranged from 29 to 46 minutes [1,14,17,22]. D2N time has been shown to have a significant impact on both in-hospital and 30-day mortality for patients following STEMI, with in-hospital mortality increasing from $2.9 \%$ in patients with D2N times under 30 minutes to $4.1 \%$ with D2N times from 31 to 45 minutes, and $6.2 \%$ if D2N time exceeded 45 minutes $[1,25]$. Given the proportion of STEMI patients treated with fibrinolysis and the impact D2N time has on patient outcomes, reducing D2N time for our study population should be a priority. One factor likely to improve D2E and D2N times in our study population is to increase EMS utilization by patients with symptoms of ACS. Only 35.0\% of STEMI patients in the current study arrived by EMS, far below the national average of $61.3 \%$ [26]. Studies have shown that presenting by ambulance cuts the time it takes to be seen by an ED physician in half, reduces the time from symptom onset to arrival at hospital by 31 minutes, and reduces D2E time by 3 minutes [26]. EMS-administered prehospital ECG (PHECG) for patients with STEMI symptoms has been shown to decrease D2N time by up to 36 minutes without substantially increasing time on scene, is a component of contemporary international guidelines for STEMI [4-5,27], and is being introduced in New Brunswick. These findings suggest that the implementation of a PHECG program, alongside increases in EMS utilization in the province, may result in reduced D2E and D2N times and improve STEMI outcomes. Increasing EMS utilization in the province would be challenging and require widespread public education through media campaigns; however, our results indicate that it represents a significant area for potential improvement in our province.

An important limitation of the current study is the inability to estimate accurately the total ischemic time from symptom onset. In our study, as well as many others on the topic, time from symptom onset is substituted for time of FMC, leaving approximately 60 minutes of prehospital ischemic time out of scrutiny [28]. Additional limitations of the current study include the omission of patients referred to out-of-province PCI centers, less than $3 \%$ of the overall volume, from the NBHC database, and the lack of initial non-diagnostic ECGs in patients who subsequently develop diagnostic ST changes. Furthermore, the treatment quality measures used in the current study are surrogates for the true mortality risk factor in STEMI, which is the total ischemic time from symptoms onset.

\section{Conclusions}

Measurements for the quality of care for STEMI did not vary by volume of STEMI patients seen. There was no difference in the rates of adherence to established STEMI care delivery guidelines between high-, medium-, and low-volume centers in the province of New Brunswick. However, the overall rates of adherence were well below the rates set by international guidelines. We recommend a further system analysis and changes at the levels of public awareness, triage, emergency department pathways, and communication and transfers within the provincial cardiac care system, to identify and correct factors that delay the diagnosis and 
treatment of STEMI patients across the province.

\section{Additional Information \\ Disclosures}

Human subjects: All authors have confirmed that this study did not involve human participants or tissue. Animal subjects: All authors have confirmed that this study did not involve animal subjects or tissue. Conflicts of interest: In compliance with the ICMJE uniform disclosure form, all authors declare the following: Payment/services info: All authors have declared that no financial support was received from any organization for the submitted work. Financial relationships: All authors have declared that they have no financial relationships at present or within the previous three years with any organizations that might have an interest in the submitted work. Other relationships: All authors have declared that there are no other relationships or activities that could appear to have influenced the submitted work.

\section{Acknowledgements}

We would like to acknowledge Ms. Jacqueline Fraser and Miss Jordyn Atkinson for their help and support with this project.

\section{References}

1. Gibson CM, Pride YB, Frederick PD, et al.: Trends in reperfusion strategies, door-to-needle and door-to-balloon times, and in-hospital mortality among patients with ST-segment elevation myocardial infarction enrolled in the National Registry of Myocardial Infarction from 1990 to 2006. Am Heart J. 2008, 156:1034-1044. 10.1016/j.ahj.2008.07.029

2. Jernberg T, Johansen P, Held C, Svennblad B, Lindback J, Wallentin L: Association between adoption of evidence-based treatment and survival for patients with ST-elevation myocardial infarction. JAMA. 2011, 305:1677-1684. 10.1001/jama.2011.522

3. Danchin N, Coste P, Ferrières J, et al.: Comparison of thrombolysis followed by broad use of percutaneous coronary intervention with primary percutaneous coronary intervention for STsegment-elevation acute myocardial infarction: data from the French registry on acute STelevation myocardial infarction (FAST-MI). Circulation. 2008, 118:268-276. 10.1161/CIRCULATIONAHA.107.762765

4. O'Gara PT, Kushner FG, Ascheim DD, et al.: 2013 ACCF/AHA guideline for the management of ST-elevation myocardial infarction: a report of the American College of Cardiology Foundation/American Heart Association Task Force on Practice Guidelines. Circulation. 2013, 127:362-425. 10.1016/j.jacc.2012.11.019

5. Task Force on the management of ST-segment elevation acute myocardial infarction of the European Society of Cardiology (ESC), Steg PG, James SK, et al.: ESC guidelines for the management of acute myocardial infarction in patients presenting with ST-segment elevation. Eur Heart J. 2012, 33:2569-2619. 10.1093/eurheartj/ehs215

6. Patel AB, Tu JV, Waters NM, et al.: Access to primary percutaneous coronary intervention for ST-segment elevation myocardial infarction in Canada: a geographic analysis. Open Med. 2010, 4:13-21.

7. Larson DM, Duval S, Sharkey SW, et al.: Safety and efficacy of a pharmaco-invasive reperfusion strategy in rural ST-elevation myocardial infarction patients with expected delays due to long-distance transfers. Eur Heart J. 2012, 33:1232-1240. 10.1093/eurheartj/ehr403

8. Pu J, Ding S, Ge H, et al.: Efficacy and safety of a pharmaco-invasive strategy with half-dose alteplase versus primary angioplasty in ST-segment-elevation myocardial infarction: EarlyMYO trial (early routine catheterization after alteplase fibrinolysis versus primary PCI in acute ST-segment-elevation myocardial infarction). Circulation. 2017, 136:1462-1473.

10.1161/CIRCULATIONAHA.117.030582

9. Chakrabarti A, Krumholz HM, Wang Y, Rumsfeld JS, Nallamothu BK: Time-to-reperfusion in patients undergoing interhospital transfer for primary percutaneous coronary intervention in the U.S: an analysis of 2005 and 2006 data from the National Cardiovascular Data Registry. J 
Am Coll Cardiol. 2008, 51:2442-2443. 10.1016/j.jacc.2008.02.071

10. Hannan EL, Zhong Y, Jacobs AK, et al.: Effect of onset-to-door time and door-to-balloon time on mortality in patients undergoing percutaneous coronary interventions for st-segment elevation myocardial infarction. Am J Cardiol. 2010, 106:143-147.

10.1016/j.amjcard.2010.02.029

11. McNamara RL, Wang Y, Herrin J, et al.: Effect of door-to-balloon time on mortality in patients with ST-segment elevation myocardial infarction. J Am Coll Cardiol. 2006, 47:2180-2186. 10.1016/j.jacc.2005.12.072

12. Nallamothu B, Fox KA, Kennelly BM, et al.: Relationship of treatment delays and mortality in patients undergoing fibrinolysis and primary percutaneous coronary intervention. The Global Registry of Acute Coronary Events. Heart. 2007, 93:1552-1555. 10.1136/hrt.2006.112847

13. Cannon CP, Brindis RG, Chaitman BR, et al.: 2013 ACCF/AHA key data elements and definitions for measuring the clinical management and outcomes of patients with acute coronary syndromes and coronary artery disease: a report of the American College of Cardiology Foundation/American Heart Association Task Force on clinical data standards (writing committee to develop acute coronary syndromes and coronary artery disease clinical data standards). J Am Coll Cardiol. 2013, 61:992-1025. 10.1161/CIR.0b013e3182831a11

14. Janda SP, Tan N: Thrombolysis versus primary percutaneous coronary intervention for ST elevation myocardial infarction at Chilliwack General Hospital. Can J Cardiol. 2009, 25:382384. 10.1016/S0828-282X(09)70165-5

15. Tsai CL, Magid DJ, Sullivan AF, et al.: Quality of care for acute myocardial infarction in 58 U.S. emergency departments. Acad Emerg Med. 2010, 17:940-950. 10.1111/j.15532712.2010.00832.x

16. Diercks DB, Kirk JD, Lindsell CJ, Pollack CV Jr, Hoekstra JW, Gibler WB, Hollander JE: Door-toECG time in patients with chest pain presenting to the ED. Am J Emerg Med. 2006, 24:1-7. 10.1016/j.ajem.2005.05.016

17. Atzema CL, Austin PC, Tu JV, Schull MJ: Effect of time to electrocardiogram on time from electrocardiogram to fibrinolysis in acute myocardial infarction patients. CJEM. 2011, 13:7989. 10.2310/8000.2011.110261

18. Armstrong PW, Gershlick A, Goldstein P, et al.: The strategic reperfusion early after myocardial infarction (STREAM) study. Am Heart J. 2010, 160:30-35. 10.1016/j.ahj.2010.04.007

19. Thorn S, Attali P, Boulenc JM, et al.: Delays of treatment of acute myocardial infarction with ST elevation admitted to the CCU (coronary care unit) in Alsace [Article in French]. Arch Mal Coeur Vaiss. 2007, 100:7-12.

20. Atzema CL, Schull MJ, Austin PC, Tu JV: Temporal changes in emergency department triage of patients with acute myocardial infarction and the effect on outcomes. Am Heart J. 2011, 162:451-459. 10.1016/j.ahj.2011.05.015

21. Atzema CL, Austin PC, Tu JV, Schull MJ: ED triage of patients with acute myocardial infarction: predictors of low acuity triage. Am J Emerg Med. 2010, 28:694-702. 10.1016/j.ajem.2009.03.010

22. Bradley EH, Herrin J, Wang Y, et al.: Door-to-drug and door-to-balloon times: where can we improve? Time to reperfusion therapy in patients with ST-segment elevation myocardial infarction (STEMI). Am Heart J. 2006, 151:1281-1287. 10.1016/j.ahj.2005.07.015

23. Coyne CJ, Testa N, Desai S, Lagrone J, Chang R, Zheng L, Kim H: Improving door-to-balloon time by decreasing door-to-ECG time for walk-in STEMI patients. West J Emerg Med. 2015, 16:184-189. 10.5811/westjem.2014.10.23277

24. Purim-Shem-Tov YA, Rumoro DP, Veloso J, Zettinger K: Emergency department greeters reduce door-to-ECG time. Crit Pathw Cardiol. 2007, 6:165-168. 10.1097/HPC.0b013e31815b565d

25. McNamara RL, Herrin J, Wang Y, et al.: Impact of delay in door-to-needle time on mortality in patients with ST-segment elevation myocardial infarction. Am J Cardiol. 2007, 100:12271232. 10.1016/j.amjcard.2007.05.043

26. Diercks DB, Kontos MC, Chen AY, et al.: Utilization and impact of pre-hospital electrocardiograms for patients with acute ST-segment elevation myocardial infarction: data from the NCDR (National Cardiovascular Data Registry) ACTION (Acute Coronary Treatment and Intervention Outcomes Network) registry. J Am Coll Cardiol. 2009, 53:161-166. 10.1016/j.jacc.2008.09.030 


\section{Cureus}

27. Morrison LJ, Brooks S, Sawadsky B, McDonald A, Verbeek PR: Prehospital 12-lead electrocardiography impact on acute myocardial infarction treatment times and mortality: a systematic review. Acad Emerg Med. 2006, 13:84-89.

28. Armstrong PW, Gershlick AH, Goldstein P, et al.: Fibrinolysis or primary PCI in ST-segment elevation myocardial infarction. N Engl J Med. 2013, 368:1379-1387. 10.1056/NEJMoa1301092 